\title{
Augmented Reality in Science Education: An Application in Higher Education
}

\section{OPEN ACCESS}

Manuscript ID:

EDU-2021-09033907

Volume: 9

Issue: 3

Month: June

Year: 2021

P-ISSN: 2320-2653

E-ISSN: 2582-1334

Received: 17.03.2021

Accepted: 12.05 .2021

Published: 01.06.2021

Citation:

Yilmaz, Ozkan.

"Augmented Reality in Science Education: An Application in Higher Education." Shanlax International Journal of Education, vol. 9, no. 3, 2021, pp. 136-148.

DOI:

https://doi.org/10.34293/ education.v9i3.3907

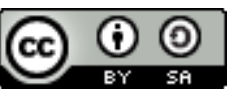

This work is licensed under a Creative Commons Attribution-ShareAlike 4.0 International License

\author{
Ozkan Yilmaz \\ Faculty of Education, Department of Mathematics and Science Education \\ Erzincan Binali Yildirim University, Erzincan, Turkey \\ https://orcid.org/0000-0001-8963-3354
}

\begin{abstract}
Effective usage of augmented reality $(A R)$ depends on good integration into the learning environment. Based on a qualitative research approach, this study investigates the effects of using AR technologies in science education to support the effective use of AR. Students' experiences of $A R$ were gathered using a prepared questionnaire form. Within the scope of science education, $A R$ was used in a university-level chemistry course. Using theme analysis, descriptive themes were created by analyzing the content of completed questionnaires in written texts. Descriptive expressions obtained from the written text were determined by free coding. These codes were then matched with appropriate themes and illustrated in the form of branched trees. The study results demonstrated that AR is an optimal tool for teaching abstract subjects that do not feature direct observation and examination in science education. Students also have positive opinions about the use of AR in other courses in science education. Another important result from this study revealed that AR software interfaces require improvements to be suitable as teaching material. In addition, several recommendations have been presented for the better integration of AR into the learning environment.
\end{abstract}

Keywords: Augmented reality, Science education, Higher education, Student perception

\section{Introduction}

Internet (information and communication) technologies have changed our daily lives and, in the 21st century, are considered up-and-coming tools for improving education (Salmi, et al., 2017). However, it is necessary to develop augmented reality (AR) technology in the field of education by conducting new research (Dalim, et al., 2017). AR is also a growing area of interest for promoting inclusive learning (Bacca, et al., 2014). Students have expressed that AR allows them to learn in an easier and more fun way (Toledo-Morales \& Sanchez-Garcia, 2018). There has recently been an increasing number of publications on the use of AR in education (Dalim, et al., 2017), and both effective and ineffective dimensions have been identified. The former include increased understanding of subject content and increased student motivation, while the latter include ineffectual classroom integration and learner differences (Radu, 2014). With new technological developments, the utility of AR technology should improve and research should provide more insights into its effective application in the field of education shortly (Akçayır \& Akçayır, 2017). 


\section{Definition of Augmented Reality}

AR has been used in various fields from past to present, including the training of pilots, medical education, and engineering, among others. (Akçayır, et al., 2016). In the broadest terms, AR can be defined as a computer-generated image that overlays virtual objects (augmented components) into the real world (Akçayır \& Akçayır, 2017; Dalim, et al., 2017) by using a display device in a real-world environment (Huang, et al., 2016). Such technology works interactively and in real-time (Javornik, 2016).

Another technology in which real and virtual environments are used is virtual reality (VR), although VR adopts completely different approaches. The main difference is that AR uses virtual knowledge to develop the real world while viruses the elements of the real world to create virtual environments (Dalim, et al., 2017). Despite this difference, both aim to enhance the personal sensorial environment (Gandolfi, 2018).

Some researchers have also described mixed/ merged reality (MR) (McMillan, et al., 2017), which differs somewhat from AR and VR. For example, Intel has developed a virtual reality headset, described as a "merged reality" device, that allows nearby objects from the real world to be integrated into a new computer-generated view (Intel, 2016). However, both AR and MR use the same image source, environment, display devices, perspective, and presence; they differ in terms of awareness (McMillan, et al., 2017). In AR, virtual objects can be identified by their nature and behavior, while in $\mathrm{MR}$, it is not possible to distinguish the smoothly rendered virtual objects from real objects.

\section{Types of AR Technology}

Today, there are five different types of AR technology: projection-based, recognition-based, location-based, outlining, and superimpositionbased. Projection-based AR technology is anchored in advanced projection technology, which simplifies the complex hands-on tasks of a company's manufacturing and training operations (Ryznar, 2019). Recognition-based AR is used for object recognition and provided more information about the given object (digit, 2019). For instance, when shopping, people may use their mobile phones to scan barcodes or $\mathrm{QR}$ codes to acquire more information on a product. This technology provides mobile phone camera recognition of special signs and then acquires information via the internet. As the name implies, location-based AR is a technology designed for use in a specifically designated area, for example, in schools or other surroundings (Wu, et al., 2013). It benefits learners by bringing a sense of authenticity (Wu, et al., 2013). Outlining AR uses an object recognition camera and technology similar to projection-based AR (greet, 2019). While the human eye is the best camera, it has some limitations. For example, it cannot see infrared lights, and in low light conditions, it does not see clearly and cannot see far away objects. Therefore, special cameras have been designed for such cases (digit, 2019). For instance, some new car models feature a headsup display (HUD) that the driver uses to obtain more information on the dashboard while driving. Super imposition-based AR uses object recognition technology, making it possible to replace an entire object or part thereof with an augmented view (greet, 2019). Superimposing a real object with its internal view may help in education; for instance, it can study bone structure in anatomy (digit, 2019).

While in principle, AR varieties have similar characteristics, different types of technological infrastructure and usage areas require diverse types of AR. For example, the fields of engineering, health, education, and training each has their unique problems; thus, ARs with different technological infrastructures must solve them. In the education field, two types of AR are used predominantly: recognition-(marker) based and location-based (Fleck, et al., 2015; Hanafi, et al., 2016; Huang, et al., 2016; Kamarainen, et al., 2018; Lisabeth \& Helen, 2017; Nielsen, et al., 2016; Nikou \& Economides, 2016; Yoon, et al., 2017; Zainuddin, et al., 2016). In addition, these studies demonstrate that, in the education field, AR technology uses mobile technology and suitable software and the applications of AR research can now be found on both mobile and non-mobile devices (Bacca, et al., 2014). However, mobile technologies (particularly mobile phones) are used more than non-mobile devices in education. 


\section{Some Studies on AR}

Different kinds of academic studies have been conducted worldwide on the use of AR, one of the developing new technologies in education and training. Some of these are as follows. In science education, AR has been used to teach nature's invisible physics forces (Andersson, et al., 2016); in dental education, for clinical training (Dutã, et al., 2011); and in K-12 schools, to teach astronomical concepts (Fleck, et al., 2015). Other research on $\mathrm{AR}$ has examined its use to improve undergraduate students' learning (Hanafi, et al., 2016), to create a reality-based experimental learning environment (Huang, et al., 2016), to demonstrate the effects on consumer behavior (Javornik, 2016), to provide abstract-concept learning in math education $(\mathrm{Li}$, et al., 2017), to visualize abstract concepts for science education (Andersson, et al., 2016), to promote collaborative and autonomous learning in higher education (Martín-Gutiérrez, et al., 2015), to improve outdoor educational activity (Nikou \& Economides, 2016), to teach the English alphabet to kindergarten children (Safar, et al., 2017), to explore motivational and cognitive aspects related to AR in an informal learning context (Salmi, et al., 2017), to implement a place-based augmented reality game (Squire \& Jan 2007), and to provide a conceptual understanding of challenging science content (Yoon, et al., 2017). As can be seen, AR is just starting to break out of its infancy with new research and has begun to provide a new perspective to learning in different disciplines. $\mathrm{AR}$ is coming to be used increasingly more in the educational setting; however, considering that each discipline has its specific learning and teaching activities, new studies are needed for all disciplines, especially in science education, which will be discussed in more detail in the next section.

\section{Research Purpose}

AR technology continues to be integrated into our lives worldwide. However, to improve such integration in certain areas, it is important to implement new academic studies. For example, there is a lack of research on AR and education, particularly in science education. Cheng and Tsai (2013) noted that $\mathrm{AR}$ has the potential for pedagogical applications, but it is still in its infancy in science education. AR offers new learning opportunities, but it also creates new challenges for educators ( $\mathrm{Wu}$, et al., 2013). To solve these challenges and foster much more effective learning, it is important to take students' experiences into consideration. Special AR system designs based on users' needs are important (Garzón, et al., 2017) because user experience helps promote acceptance and adoption. User experience also aids in developing AR technology for educational purposes by helping to define appropriate tools and the proper integration of learning objectives (Arifin, et al., 2018). Considering that each learning and teaching area, including science education, has its characteristics and needs, it can be said that it is essential to integrate AR in ways specific to each field of education.

Science education can be divided into physics, chemistry, and biology topics, including abstract subjects such as the "periodic table and properties of the elements" in chemistry. In this subject, it is not possible for students to interact directly with the learning situation (using sight, touch, hearing, etc.). Still, they are required instead to reach abstract conclusions by thinking through abstract concepts. This makes it difficult to learn and configure new information in science education. To date, laboratories have been important places where students can interact directly with science situations. Laboratories develop individual experiences, provide an understanding of scientific facts and concepts, develop students' ability to identify questions and concepts, allow students to learn how to use the tools and rules of science, help students to understand the values and assumptions required to develop and interpret scientific knowledge,and develop students' ability to collaborate effectively with others in performing special tasks (Singer, et al., 2006).

However, advancing technologies have now begun introducing a new dimension to science education through online or virtual laboratories. A virtual lab is an online lab that can be accessed from many locations and at any time without being tied to a specific building (Salihbegovic \& Ribic, 2008). Virtual labs are software simulations that can help students to visualize complex relationships during classroom teaching or individual learning at home (Salihbegovic \& Ribic, 2008). Virtual and remote 
labs reduce the costs associated with conventional hands-on labs as they require no special laboratory equipment or materials. They also increase safety as they do not require dangerous experimentation (Heradio, et al., 2016).

Furthermore, while a limited number of people can work in physical laboratories, many people can work simultaneously in virtual laboratories (Kratzke, 2012). These advantages mean that virtual laboratories have begun to gain importance in science education and seem to have replaced physical laboratories to some extent. Nevertheless, physical laboratories remain important and are still the best way to acquire hands-on experience in operating laboratory devices and conducting experiments (Salihbegovic \& Ribic, 2008). Some researchers have even decried to switch from real to completely virtual laboratories in science education (Akçayır, et al., 2016). In real laboratories, students engage in a hands-on activity, which "increase[s] learning, increase[s] motivation to learn, [and] increase[s] enjoyment of learning, independent learning and decision-making, and advanced communication skills" (Haury \& Rillero, 1994). Moreover, in real laboratories, students work in teams with tutorial help from their teacher (Salihbegovic \& Ribic, 2008).

Both physical and virtual laboratories have their unique strengths and weaknesses, though, by comparison, AR can be said to be more effective in certain regards. With AR, students can work with virtual images, then work with real samples and carry out experiments in a physical environment when needed. Positive results are being obtained for the use of AR in science teaching. Using AR technology increases students' laboratory skills and their positive attitudes towards the physical laboratory (Akçayır, et al., 2016). Moreover, it affords students the opportunity to use and display multi-dimensional content that is not visible or is difficult to show in a classroom environment (MacCallum \& Jamieson, 2017).

Today, the interactive learning environment provided by AR technology can improve learning structure. Thus, the purpose of this study is to provide an in-depth investigation of students' experiences using AR in science education. Users' expectations are required to determine the acceptance of this technology in the field of education and to ensure appropriate interaction(Dalim, etal., 2017). However, users' experiences are often overlooked in AR applications, and there are no measurement standards for user experiences of the effective application of AR in education (Arifin, et al., 2018). As a result of a literature review, Akçayır and Akçayır (2017) emphasized that in future academic studies, learners views and preferences should be determined to use AR more effectively in the learning environment. The results obtained from the studies in this literature review guide solving problems in teaching design. Additionally, these results contribute to developing the principles of the AR teaching model design (Wu, et al., 2013) and provide more evidence regarding how to best design and organize such learning activities (Tomara \& Gouscos, 2014). Field research is also required to enable educators to use the most suitable applications (Wang, et al., 2018).

Within this context, the research questions addressed by this study are as follows:

First, we investigate different and useful AR in science education compared to traditional teaching (without AR) in the classroom and ask: (1) What differences does AR use bring to the science learning environment?

Second, to determine the use of AR in the right place and right learning area, we examine which lessons and subjects benefit from AR use and ask: (2) Which courses and what kind of subjects are suitable for AR use?

Third, to use AR effectively, software, hardware, and user dimensions must be considered. Thus, we ask: (3) What are students' suggestions for effective use of AR?

Finally, to make a general evaluation after AR application, the strongest and weakest aspects were examined with the following question: (4) What is the effectiveness of AR in science teaching?

It is hoped that the results of this study will help design a set of instructional patterns and design principles for AR environments to resolve issues involved in instructional design in science education. The study results will provide support for the effective use of AG, one of the new technologies being used to create an improved learning environment in science education. 


\section{Method}

This study adopted a qualitative research approach, which focuses on social phenomena and uncovers the feelings and perceptions of participants (Lodico, et al., 2006). In this approach, qualitative interviews are used to elicit in-depth knowledge from participants regarding particular phenomena, experiences, or sets of experiences (Demarais, 2004). To procure students' experiences based on AR application, a questionnaire form was used to collect data, while thematic analysis was used to analyze that data. More detailed information on the methodology is provided below.

\section{Participants}

The participants constituted students from the Department of Science Education at the Education Faculty in eastern Turkey. The study was carried out in a class of 42 students enrolled in the department's chemistry course. Since the study's focus was on using AR in science teaching, suitable science courses were examined. When the subject content, physical laboratory facilities, and necessary internet infrastructure facilities were taken into consideration, it was decided that the chemistry course was the most appropriate. However, only 37 students (27 female, 10 male aged 18-24) attended regularly. All students enrolled in the course were subject to the AR application, but opinions on implementation were taken voluntarily. All of the 37 regularly attending students expressed their opinions.

\section{Data Collection and Data Collection Tools}

A self-developed instrument was used to gather students' experiences with AR. Such instruments have been used in the past to gather the perceptions of a specific setting or group of participants on current educational issues (Lodico, et al., 2006).

A prepared questionnaire form was used to collect data. In terms of design, questionnaires can be more or less structured,and it is important to give respondents the freedom to share their thoughts (Coolican, 1999). Therefore, in this study, a structured but open-ended questionnaire form was used, giving students the freedom to answer but guided by eight specific open-ended questions: (1) What was the most effective aspect of the course that applied AR? (2) What was the least effective aspect of the course that applied AR? (3) In the future, what suggestions do you have for students who take a course that includes an AR practice? (4) What are your suggestions for a better AR practice? (5) If you compare the lesson that applied AR with other lectures, what is the most important difference? (6) In what other courses would you like to use AR? (7) Concerning the previous question, why did you select those lectures or courses? (8) If you have anything that you would like to share, write as you wish. The digital version of the questionnaire was then uploaded to the internet, and the students responded using their mobile phones or computers. Data were collected at the end of the test course in one round. Thematic analysis, classified under qualitative descriptive design (Vaismoradi, et al., 2016), was used to analyze the data. There is no fixed path for thematic analysis when reading data in the form of written text(Braun \& Clarke, 2006). Inductive or theoretical thematic analysis can be used depending on the research purpose. Since this study is a descriptive study based on student opinions about AR application, there was no particular theoretical background. Therefore, an inductive analysis technique was chosen. First, the statements given for each question were classified through free coding. After all the coding was complete, themes were inductively determined. Finally, each theme and related codes were visualized in a branched-tree view. Nvivo PC software was used in every step of the data analysis.

\section{Implementation Procedure}

Previous studies have shown that mobile phones and more stable software are preferred for use in learning environments (Akçayır \& Akçayır, 2017). A further advantage is that most students have their smartphones, thus avoiding extra costs for special equipment. AR is rapidly becoming more powerful and less expensive due to its availability on mobile devices (Craig, 2013). For this reason, mobile phones and science-related software were selected for use in this study.

The Elements 4D mobile application was used to create AR. This application works on any mobile device that has a camera and internet connectivity. 
Before commencing the lesson, all students installed the mobile application on their mobile phones, and the teacher checked the internet connectivity of all phones. Students could use their mobile internet connection or the free Wi-Fi network provided in class if they did not have or want to use their mobile data packages.

The laboratory classroom was used for the AR instruction. Laboratory classes are specifically designed for students to work individually or in teams, and seating positions can be changed if required.

This study was conducted within the context of the General Chemistry I course, an atheoretical course that is taught for four class hours per week in a science laboratory under the control of an instructor, who offers guidance and assistance when students need it. In laboratory activities, students conduct experiments in groups of three or four. No criteria were used to create student groups, and students were allowed to form groups freely. They could use the AR objects either individually or with their group (see Fig. 1).
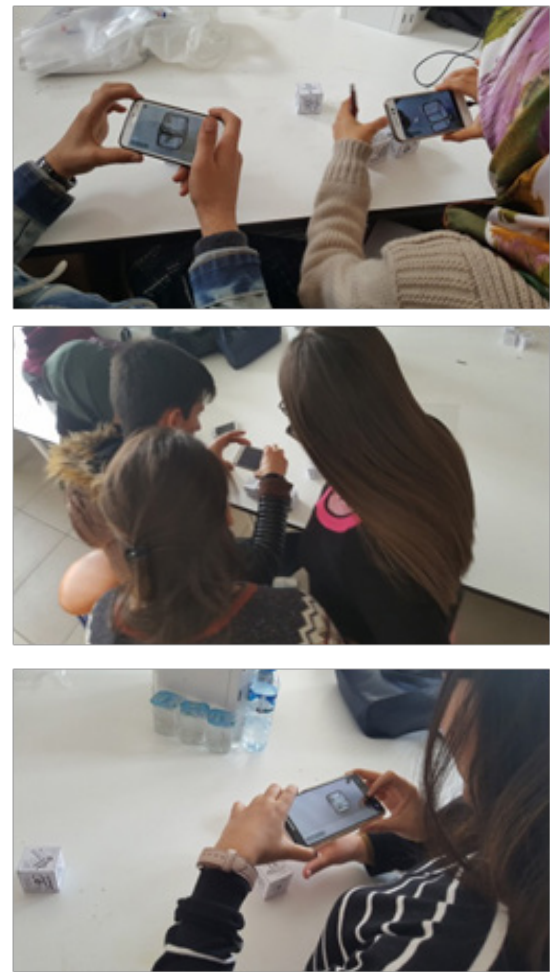

Figure 1: Sample Pictures from Student Studies
The application used a specific topic in general chemistry (Periodic Properties of the Elements). Students learn to classify matter, explain the electronic structure of the atom, construct electron configurations in the atom, and describe the periodic properties of elements. The application was planned for five weeks. In the first week, the course software was introduced to the students, and three-dimensional objects were prepared that were integrated with the software. The students used AR applications in the laboratory through their own mobile devices. If for any reason, there was a technical problem with a student's phone, they used the phones of other members of their group (see Fig.2). The application was performed for the next three weeks, and then, in the final week, students' views were collected through specific questionnaire forms.

In each lesson, the teacher used an AR application that followed the sequence described in Fig. 2 below.

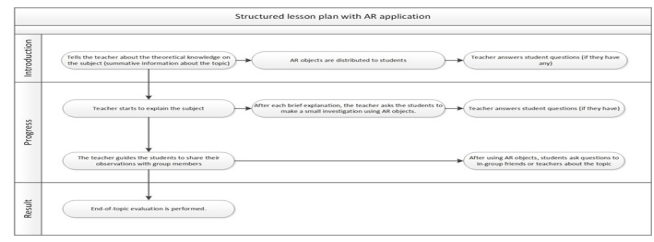

Figure 2: Lesson plan

\section{AR Material}

Recognition-based was used in this application, and three-dimensional cardboard objects were prepared for use (see Fig.3). These objects had markers and symbols on all surface areas and worked with special mobile phone software that used the phone camera to recognize the special symbols on the surfaces. Moreover, students could see all the chemical elements in AR. The mobile phone app also had some specific features, allowing students to open and close the information about the chemical element on the screen.

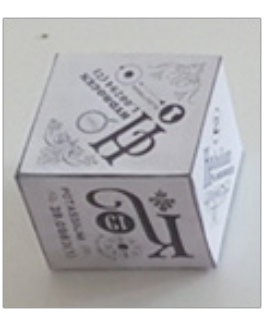

AR Object

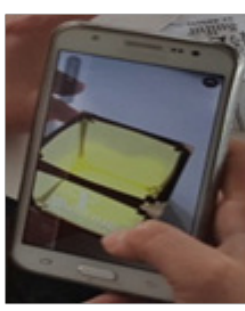

AR Visualization 


\section{Results}

User experience is important for the effective use of AR in education. It provides further evidence about how to best design and organize learning activities and apply the right pedagogy. Therefore, in the present study, students' opinions on user experience were divided into four special themes, further conceptualized by nodes and sub-nodes, with some nodes occurring under more than one theme. The purpose of presenting the findings in this way is to demonstrate the situation as descriptively as possible. After all the themes have been presented, the overall presentation of findings is summarized at the end of the section.

\section{First Theme: Dimensions}

This theme includes two nodes and 11 sub-nodes. Under the "different dimension" node, there are six sub-nodes that were referenced 13 times in total. The node "remarkable" was the most commonly referenced by students, demonstrating that "different dimensions" of AR are remarkable, depending on other teaching materials. As shown in Fig.4, AR is effective in the constructive learning environment and provides versatile information. Another important point is that AR presents a new way of conducting an experiment in science education. Students expressed that AR is suitable for the new century and provides up-to-date information in a factually connected way, not just abstractly.

The students also observed that AR could be very useful. The most useful dimension is "learning by doing," which students referenced nine times. While learning can occur in many different environments, the students considered the most beneficial aspect of AR to be the opportunity to learn by experience. At the same time, the second most useful dimension is "reality."For example, the atom and its structure are abstract phenomena that cannot be observed directly. However, since AR allows these phenomena to be observed, the students consider it useful in demonstrating reality. As a part of learning by doing, students also stated that AR is very useful in allowing active participation in the course by observing experiments or investigating activities.

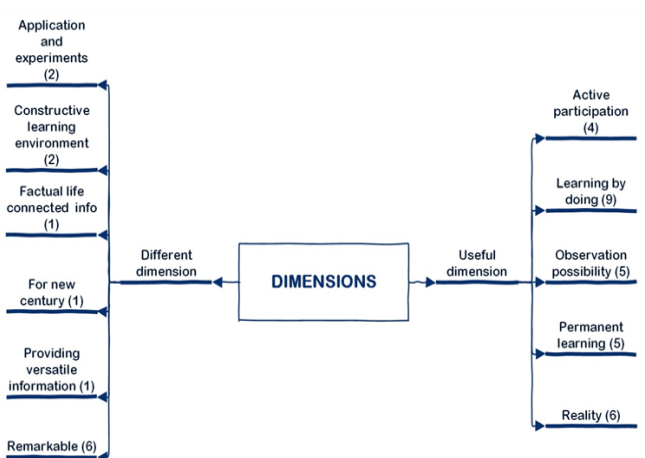

Figure 4: Dimensions

\section{Second Theme: Suggestions for Courses}

As shown in Fig. 5, following the application of AR in chemistry class, students expressed their opinions about which courses (e.g., history, geography) should integrate AR in the future and why. In response, students stated that AR should be used in all courses and laboratories, particularly in biology and biology laboratory, astronomy, chemistry, geography, history, and physics courses. These courses are difficult to understand, contain abstract subjects, and are more suitable for AR. Regarding biology and biology laboratory, they shared the idea that AR could be used as a microscope and would be effective in analyzing living things. Regarding history, they noted that AR would allow history to be experienced in a living way.

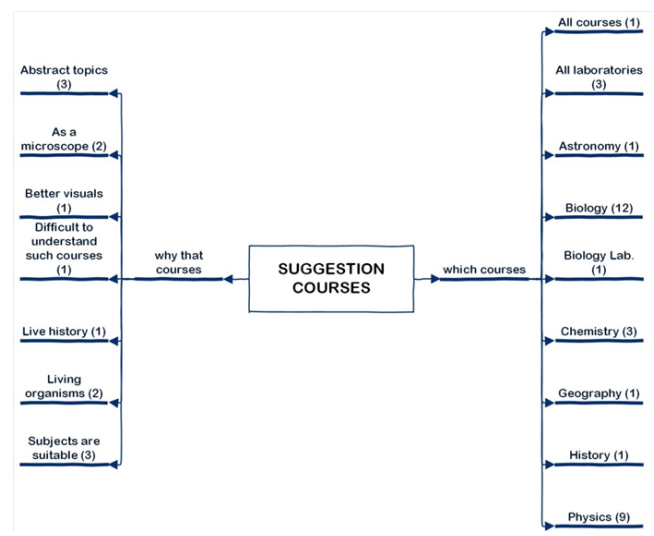

Figure 5: Suggested courses

\section{Third Theme: Suggestions}

Students shared their suggestions under the two sub-nodes, "improvement of AR" and "suggestions for future users." Since these ideas were to develop and use AR more effectively, their top priority 
was related to the software (referenced six times), with students suggesting new features that could be added to it. Time management was the second most important concern specified by students. Other important aspects are shown in Fig. 6.

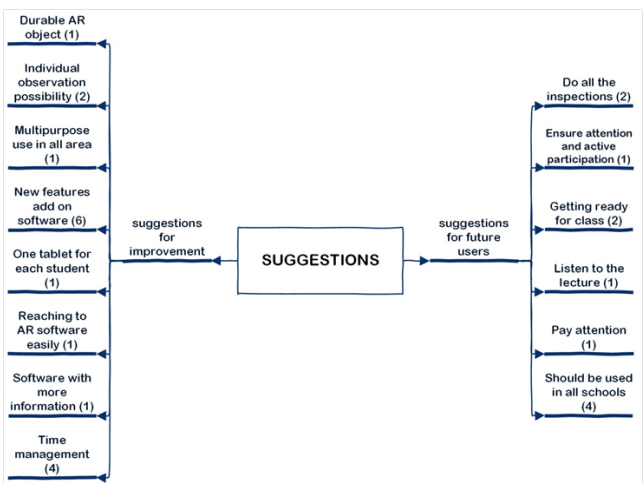

Figure 6: Suggestions

The students then presented some general recommendations for future students using this practice, including course attendance, listening to the course carefully, and preparing for the course. All recommendations are shown in Fig. 6.

\section{Fourth Theme: Effectiveness}

As shown in Fig. 7, three strengths and four weaknesses of AR were identified. Among the strengths of AR, "reality" was the point most emphasized by students and upon which almost all students agreed. The second strength of AR is to provide learning by doing. Furthermore, although this aspect was only expressed by one student, the interaction seems to be one of the most effective aspects of AR.

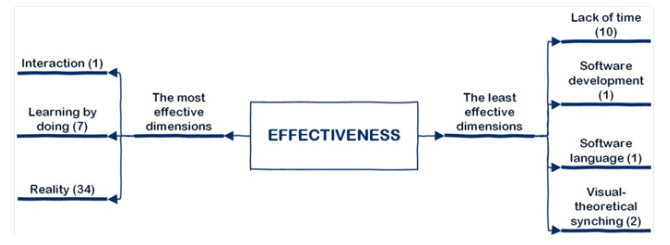

Figure 7: Effectiveness of AR

When considering the weaknesses of AR, students most often cited "lack of time" spent in AR sessions (in other words, the individual AR sessions were too short)as negatively impacting AR's effectiveness (Fig. 7). The other three least effective dimensions related to AR software: software development, software language, and visual-theoretical syncing.
As seen in Fig.7, of these four dimensions, lack of time is the most critical problem to be solved to ensure optimally effective AR-supported learning in science education.

\section{Discussion}

When evaluating students' views about the effectiveness of AR use in science education in general, the findings fell under the following headings:

\section{AR-Based Learning Environments in Science Education}

The use of $\mathrm{AR}$ in science education makes a significant difference (Fig.4, node: remarkable). To determine the reason for this difference, when students' opinions are examined, it can be observed that $\mathrm{AR}$ application provides a new perspective on the experimental activities performed in laboratories, which hold an important place in science education (Fig.4, node: application and experiments). Normally, students can use visual tools such as pictures, videos, or animation to learn about the physical structure and properties of a chemical element. However, the ability to examine with these tools is limited. On the other hand, using AR, it is possible to examine the physical structure of each element in 3-D, to compare it with other elements, and be guided by the information seen on the mobile phone screen. AR provides a unique path of discovery through a real-life symbiosis between technology and learning (Wang, et al., 2018). The idea that "AR provides factual life-connected info" (Fig.4, node: factual lifeconnected info) and "provides versatile information" (Fig.4, node: providing versatile information) supports that situation. Iftene and Trandabăț (2018) found a similar situation in their research. They stated that both teachers and students agreed that the lessons were more attractive when was used. AR also supports the teacher to better present new subject content, while students welcomed the visual material support provided by AR (Akçayır, et al., 2016).

In science education, laboratories are used for different purposes, including supporting the content and concepts taught in lectures, learning to conduct research, learning to conduct measurements, motivating students, \& appreciating the experimental 
nature of science (Berg, 1997). AR provides a strikingly different perspective for laboratories, which students considered remarkable, by providing the opportunity to conduct a real-life investigation \& experimental activities provide versatile information.

The most important contribution of AR in the learning environment is that it offers a learning experience by doing (Figs. 4 and 7, node: learning by doing) as in laboratories. This allows students to observe abstract concepts (Fig. 4, node: observation possibility) such as elements and their properties. Increasing involvement in learning is based on providing students with opportunities to select their methods and pace of learning (Dembo \& Eaton, 1997). At this point, it is important to provide active participation in the course. In this context, students' opinions (Fig. 4, node: active participation) suggest that AR supports the active participation of students, which is difficult to achieve, particularly considering that higher education students come from different provinces and different backgrounds (Norton, 2007). In addition to active participation, $\mathrm{AR}$ is also effective in fostering interaction among students (Fig. 7, node: interaction). The learner is at the center,and non-directive teaching is an important consideration for his/her knowledge. It is important for students to interact with other people to configure their information (Joyce, et al., 2009). In addition to all these positive effects, this study revealed that the most important contribution of AR to science education is reality (Figs. 4 and 7, node: reality), which is an important factor in the structuring of learning. It is important for the learning environment to interact as much as possible with the real situation so that information can be structured and recalled more easily.

For information to be recalled a day later, the effect order is at least as much as follows: (1) verbal processing 5-10\% (lecture, reading), (2) verbal and visual processing 20-50\% (audiovisual, demonstration, discussion group), and (3) doing 75$90 \%$ (practice by doing, immediate use of learning) (Sousa, 2006). In this context, it is vital that AR provides visual cues and, most importantly, reality and that it provides the opportunity to learn by doing. In this respect, it can be an effective learning and teaching tool in structuring and recalling information.

\section{New Applications in New Courses}

Student experiences provided information on which courses to prioritize in new AR applications (Fig. 5). When these courses are examined, it can be observed that the first three priorities will be the appropriate application of AR in biology, physics, and chemistry, respectively, and all laboratory courses. Another important finding is that AR could be used not only in science education courses but also in humanities courses such as history and geography. These areas should be prioritized for AR, as AR can facilitate a better understanding of abstract issues. When teaching abstract subjects that are difficult to understand, the use of visual perception allows AR to offer more effective learning. For example, AR can allow students to visualize historical events or microorganisms that cannot be seen with the naked eye. AR provides a high level of visualization (Videnov, et al., 2017) and seems like a good solution to visualize abstract concepts for science education (Andersson, et al., 2016). also makes an important contribution to the teaching of abstract science concepts that are difficult to learn. Abstract subjects in other courses can also be visualized to support more permanent learning.

\section{Improving AR}

Some elements should be taken into consideration when using $A R$, which is an area open to new technology and further development.

- The materials used for AR were made of cardboard and are not appropriate for repeated use due to insufficient durability. When designing AR objects, care should be taken to make them more durable and reusable.

- The use of in the school and classroom environment was observed. However, students also want to use AR outside of school for study purposes. New studies are required to examine the usability of AR in different daily living environments.

- Like other technological tools, AR has a software interface, which should be capable of adding new features. For this purpose, the interface should be provided by software developers with the necessary update support or capacity to be developed by the users with open-source 
software. Thus, more information can be provided as required. In addition, such software should be easily accessible.

- It is desirable for each student to have his/her tablet to allow them to study more individually.

- Since AR offers a new approach to the learning environment, attention should be paid to learning and teaching planning. In particular, it is necessary to plan the course time appropriately.

- The AR software interface only supports a specific language. Different language supports are required for the students to use them effectively.

\section{Conclusion}

In light of the research questions, this study has confirmed that within the scope of an innovative learning approach, AR makes a variety of novel contributions to the learning environment in terms of constructive learning. AR is the next step in education. In science education in particular, it can be used as an innovative technology to teach abstract subjects when there is no opportunity to make direct observations or gain laboratory experience. AR has the potential for use not only in science education but also in other learning areas. However, the emerging AR also has aspects that require further development, and student experiences should be considered when conducting new studies. Thus, suggestions for further studies are provided below.

\section{Future Research}

As a result of using $A R$ in science education and the evaluations of students in this study, the following issues can be investigated in the future.

First, concept teaching/learning is an important issue in science education. Students at different levels have different misconceptions, which AR can detect and eliminate. The advanced visuality of AR can help in learning abstract concepts. Extensive studies can be conducted to investigate this situation. Second, in this study, students were allowed to work individually or in groups while conducting an investigation. In subsequent AR applications, students working in teams and individuals can be examined separately. Third, new academic studies can be conducted in these fields by considering more students' opinions, which may be useful in developing AR. Fourth, new studies can be conducted to develop software, which is the basis of AR. Users also need analysis to be conducted in these development studies. Lastly, considering the needs of students, AR applications can be created not only for science education but also for other fields.

\section{Limitations}

This study used an AR application in the context of science learning. Despite the positive outputs, it also has several limitations. First, the students' opinions and evaluations of the AR application comprise subjective data and can vary. Therefore, the level of truth-clarification of the data obtained is limited by students' sincerity in sharing their experiences. Moreover, the study was conducted on a selected chemistry subject within the scope of science education. Considering that there are various subjects in physics, chemistry, and biology science education, students' experiences are limited to these selected subjects. To create effective learning with $\mathrm{AR}$, integration of pedagogy, content, and technology should be considered before implementation (Gandolfi, 2018). Thus, AR applications should target new pedagogical strategies rather than directly using traditional ones (Gandolfi, 2018).

\section{Statement on Open Data, Ethics and Conflict of Interest}

All procedures performed in studies involving human participants were by the ethical standards of the institutional and national research committee. The author declares that they have no conflict of interest. Informed consent was obtained from all individual participants included in the study. The data used in this study may be obtained by written request to the corresponding author.

\section{References}

Akçayır, Murat, and Gökçe Akçayır. "Advantages and Challenges Associated with Augmented Reality for Education: A Systematic Review of the Literature." Educational Research Review, vol. 20, 2017, pp. 1-11.

Akçayır, Murat, et al. "Augmented Reality in Science Laboratories: The Effects of Augmented Reality on University Students' 
Laboratory Skills and Attitudes toward Science Laboratories." Computers in Human Behavior, vol. 57, 2016, pp. 334-342.

Andersson, Robin, et al. "HAMLIN: An Augmented Reality Solution to Visualize Abstract Concepts for Science Education." Proceedings of SIDeR'16, 2016.

Arifin, Yulyani, et al. "User Experience Metric for Augmented Reality Application: A Review." Procedia Computer Science, vol. 135, 2018, pp. 648-656.

Bacca, Jorge, et al. "Augmented Reality Trends in Education: A Systematic Review of Research and Applications." Educational Technology \& Society, vol. 17, no. 4, 2014, pp. 133-149.

Berg, E. "Improving Teaching in the Laboratory: Old Problems, New Perspectives." Samahang Pisika ng Pilipinas, 1997.

Braun, Virginia, and Victoria Clarke. "Using Thematic Analysis in Psychology." Qualitative Research in Psychology, vol. 3, no. 2, 2006, pp. 77-101.

Cheng, Kun-Hung, and Chin-Chung Tsai. "Affordances of Augmented Reality in Science Learning: Suggestions for Future Research." Journal of Science Education and Technology, vol. 22, no. 4, 2013, pp. 449-462. Coolican, Hugh. Research Methods and statistics in Psychology. Hodder Education, 1999.

Craig, Alan B. "Mobile Augmented Reality." Understanding Augmented Reality. Elsevier, 2013, pp. 209-220.

Dalim, Che Samihah Che, et al. "Factors Influencing the Acceptance of Augmented Reality in Education: A Review of the Literature." Journal of Computer Science, vol. 13, no. 11, 2017, pp. 581-589.

deMarrais, Kathleen B. "Qualitative Interview Studies: Learning through Experience." Foundations for Research: Methods of Inquiry in Education and the Social Sciences. Lawrence Erlbaum Associates, 2003.

Dembo, Myron H., and Martin J. Eaton. "School Learning and Motivation." Handbook of Academic Learning: Construction of Knowledge. Edited by Gary D. Phye, Academic Press, 1997, pp. 65-103.
"Different Types of Augmented Reality." Digit, https://www.digit.in/technology-guides/ fasttrack-to-augmented-reality/differenttypes-of-augmented-reality.html

Dutã, Mihaela, et al. "An Overview of Virtual and Augmented Reality in Dental Education." Journal of Oral Health and Dental Management, vol. 10, no. 1, 2011, pp. 42-49.

Fleck, Stéphanie, et al. "Marker-based Augmented Reality: Instructional-design to Improve Children Interactions with Astronomical Concepts." International Conference on Interaction Design \& Children, 2015.

Gandolfi, Enrico. "Virtual Reality and Augmented Reality." Handbook of Research of K12 Online and Blended Learning. Edited by Kathryn Kennedy, and Richard E. Ferdig, ETC Press, 2018, pp. 545- 561.

Garzón, Juan, et al. “Augmented Reality Applications for Education: Five Directions for Future Research." International Conference on Augmented Reality, Virtual Reality and Computer Graphics, Springer, 2017, pp. 402-414

Hanafi, Hafizul Fahri Bin, et al. "Using a Collaborative Mobile Augmented Reality Learning Application (CoMARLA) to Improve Student Learning." International Engineering Research and Innovation Symposium, 2016.

Haury, David L., and Peter Rillero. Perspectives of Hands-On Science Teaching. ERIC Clearinghouse for Science, Mathematics and Environmental Educationm, 1994.

Heradio, Ruben, et al. "Virtual and Remote Labs in Education: A Bibliometric Analysis." Computers \& Education, vol. 98, 2016, pp. 14-38.

Huang, Tien-Chi, et al. "Animating Eco-Education: To See, Feel, and Discover in an Augmented Reality-Based Experiential Learning Environment." Computers \& Education, vol. 96, 2016, pp. 72-82.

Iftene, Adrian, and Diana Trandabăț. "Enhancing the Attractiveness of Learning through Augmented Reality." Procedia Computer Science, vol. 126, 2018, pp. 166-175. 
"Intel Unveils Project Alloy." Intel, 2016, https:// newsroom.intel.com/chip-shots/intel-unveilsproject-alloy/\#gs.5rL1mlY

Javornik, Ana. "Augmented Reality: Research Agenda for Studying the Impact of its Media Characteristics on Consumer Behaviour." Journal of Retailing and Consumer Services, vol. 30, 2016, pp. 252-261.

Joyce, Bruce R., et al. Models of Teaching. Ally and Bacon, 2009.

Kamarainen, Amy, et al. "Using Mobile LocationBased Augmented Reality to Support Outdoor Learning in Undergraduate Ecology and Environmental Science Courses." Bulletin Ecological Society of America, vol. 99, no. 2, 2018, pp. 259-276.

Kratzke, Nane. "Virtual Labs in Higher Education of Computer Science: Why They are Valuable? How to Realize? How much will It Cost?" Education, vol. 2, no. 7, 2012, pp. 239-246.

Leighton, Lisabeth J., and Helen Crompton. "Augmented Reality in K-12 Education." Mobile Technologies and Augmented Reality in Open Education. Edited by Gulsun Kurubacak, and Hakan Altinpulluk, IGI Global, 2017, pp. 281-290.

Li, Jingya, et al. "SEE ME ROAR: Self-Determination Enhanced Engagement for Math Education Relying on Augmented Reality." CHI PLAY '17 Extended Abstracts: Extended Abstracts Publication of the Annual Symposium on Computer-Human Interaction in Play, 2017, pp. 345-351.

Lodico, Marguerite G., et al. Methods in Educational Research. Wiley, 2006.

MacCallum, Kathryn, and John Jamieson. "Exploring Augmented Reality in Education Viewed Through the Affordance Lens." 8th Annual Conference of Computing and Information Technology Research and Education, 2017.

Martín-Gutiérrez, Jorge, et al. “Augmented Reality to Promote Collaborative and Autonomous Learning in Higher Education." Computers in Human Behavior, vol. 51, 2015, pp. 752-761.

McMillan, Kiki, et al. "Virtual Reality, Augmented Reality, Mixed Reality, and the Marine Conservation Movement." Aquatic
Conservation: Marine and Freshwater Ecosystems, vol. 27, 2017, pp. 162-168.

Nielsen, Birgitte Lund, et al. "Augmented Reality in Science Education - Affordances for Student Learning." Nordic Studies in Science Education, vol. 12, no. 2, 2016, pp. 157-174.

Nikou, Stavros A., and Anastasios A. Economides. "An Outdoor Mobile-Based Assessment Activity: Measuring Students' Motivation and Acceptance." International Journal of Interactive Mobile Technologies, vol. 10, no. 4, 2016, pp. 11-17.

Norton, Lin. "Using Assessment to Promote Quality Learning in Higher Education." Learning, Teaching and Assessing in Higher Education: Developing Reflective Practice. Edited by Anne Campbell, and Lin Norton, Learning Matters, 2007, pp. 92- 101.

Radu, Iulian. "Augmented Reality in Education: A Meta-Review and Cross-Media Analysis." Personal and Ubiquitous Computing, vol. 18, 2014, pp. 1533-1543.

Safar, Ammar H., et al. "The Effectiveness of Using Augmented Reality Apps in Teaching the English Alphabet to Kindergarten Children: A Case Study in the State of Kuwait." EURASIA Journal of Mathematics Science and Technology Education, vol. 13, no. 2, 2017, pp. 417-440.

Salihbegovic, Adnan, and Samir Ribic. "Development of Online Internet Laboratory." Innovative Techniques in Instruction Technology, E-learning, E-assessment, and Education. Edited by Magued Iskander, Springer, 2008, pp. 1-6.

Salmi, Hannu, et al. "Making the Invisible Observable by Augmented Reality in Informal Science Education Context." International Journal of Science Education, vol. 7, no. 3, 2017, pp. 253-268.

Singer, Susan R., et al. America's Lab Report: Investigations in High School Science. National Academies Press, 2006.

Sousa, David A. How the Brain Learns. Sage Publications, 2006.

Squire, Kurt D., and Mingfong Jan. "Mad City Mystery: Developing Scientific 
Argumentation Skills with a Place-Based Augmented Reality Game on Handheld Computers." Journal of Science Education and Technology, vol. 16, 2007, pp. 5-29.

"The 5 Types of Augmented Reality." iGreet, https:// www.igreet.co/the-5-types-of-augmentedreality/

Toledo-Morales, P., and Jose Manuel SanchezGarcia. "Use of Augmented Reality in Social Sciences as Educational Resource." Turkish Online Journal of Distance Education, vol. 19, no. 3, 2018, pp. 38-52.

Tomara, Marina, and Dimitris Gouscos. "Using Augmented Reality for Science Education: Issues and Prospects." eLearning Papers, no. 39, 2014.

Vaismoradi, Mojtabe, et al. "Theme Development in Qualitative Content Analysis and Thematic Analysis." Journal of Nursing Education and Practice, vol. 6, no. 5, 2016, pp. 100-110.

Videnov, Krum, et al. "Application of Augmented Reality in Higher Education." Journal of the
Faculty of Technics and Technologies, vol. 6, no. 1, 2018.

Wang, Minjuan, et al. "Augmented Reality in Education and Training: Pedagogical Approaches and Illustrative Case Studies." Journal of Ambient Intelligence and Humanized Computing, vol. 9, 2018.

$\mathrm{Wu}, \mathrm{Hsin}-\mathrm{Kai}$, et al. "Current Status, Opportunities and Challenges of Augmented Reality in Education." Computers \& Education, vol. 62, 2013, pp. 41-49.

Yoon, Susan, et al. "How Augmented Reality Enables Conceptual Understanding of Challenging Science Content." Educational Technology \& Society, vol. 20, no. 1, 2017, pp. 156-168.

Zainuddin, Nurkhamimi, et al. "Scaffolding a Conceptual Support for Personalized Arabic Vocabulary Learning Using Augmented Reality (AR) Enhanced Flashcards." Journal of Personalized Learning, vol. 2, no. 1, 2016, pp. 95-103.

\section{Author Details}

Ozkan Yilmaz, Faculty of Education, Department of Mathematics and Science Education,

Erzincan Binali Yildirim University, Erzincan, Turkey, Email ID: ozkanchip@gmail.com 